\title{
POR UMA JUSTIÇA RESTAURATIVA SOCIOAMBIENTAL NO BRASIL: DESAFIOS DE UM MODELO DE ALTA COMPLEXIDADE
}

\section{SOCIOENVIRONMENAL RESTORATIVE JUSTICE IN BRAZIL: CHALLENGES FACED BY A HIGH COMPLEXITY MODEL}

\section{Cristina Rego Oliveira*}

\section{RESUMO}

Reflete-se sobre a viabilidade de um modelo de justiça restaurativa socioambiental, ou seja, destinado ao tratamento de conflitos que afetam à natureza e todo o seu entorno social, especialmente nos países do sul global, tal qual o Brasil. Para assim proceder, destaca-se o estado da arte do movimento restaurativo brasileiro, apresentando as características do processo de institucionalização de práticas feito pelo Poder Judiciário, os tipos de conflitos abarcados e as ferramentas restaurativas hegemonicamente escolhidas para sua resolução (círculos de construção de paz). Na sequência, questiona-se sobre o desenvolvimento de uma nova gramática da justiça restaurativa, que por ser aplicada a crimes de maior complexidade precisaria ser reajustada, em especial frente à dificuldade de identificação das vítimas (presentes e futuras) afetadas pelo ato (e de quais seriam as suas formas de representação legítimas), dos danos causados e, ainda, de estabelecer diálogo com os ofensores, quando são empresas e corporações.

Palavras-chave: Justiça restaurativa, justiça ambiental, vítimas difusas, reparação de danos, ambiente corporativo

\section{ABSTRACT}

The article reflects on the viability of a socio-environmental restorative justice to deal with conflicts that affect nature and society, especially in countries in the global south, such as Brazil. In order to do so, the state of the art of the Brazilian restorative movement will be explained, presenting the characteristics of the institutionalization process of restorative practices carried out by the Judiciary, the types of conflicts covered and the restorative tools hegemonically adopted by judges (peacemaking circles). After that, will be questioned about the necessity to development a new grammar of restorative justice, that should be applied to complex crimes, regarding the difficulty of victim affected by the act identification (and their legitimate forms of representation), the damage caused and, also, to establish a dialogue with the offenders when they are companies and corporations.

Keywords: Restorative justice, environmental crimes, environmental justice, diffuse victimization, reparation

\footnotetext{
* Graduada em Direito pela Universidade Estadual de Londrina (2005). Especialista em Direito Penal e Criminologia pela Universidade Federal do Paraná (UFPR), em Direito Constitucional pela Academia Brasileira de Direito Constitucional (ABDCONST - Curitiba). Pós-Graduada em Sociologia Política pela Universidade Federal do Paraná. Especialista em Direito Penal Econômico Europeu pelo Instituto de Direito Penal Econômico Europeu IDPEE, vinculado à Universidade de Coimbra. Mestre em Ciências Jurídico-Criminais pela Faculdade de Direito (FDUC) da Universidade de Coimbra. Doutoranda em "Direito, Justiça e Cidadania no Século XXI" pela Faculdade de Direito (FDUC), Faculdade de Economia (FEUC) e Centro de Estudos Sociais (CES), todos da Universidade de Coimbra - Portugal. Trabalha com Justiça Restaurativa, Direito Penal e Criminologia. Associada ao European Forum for Restorative Justice (EFRJ) - Leuven/Bélgica e ao Instituto Brasileiro de Ciências Criminais - IBCCRIM. Bolsista CAPES pelo programa de Doutorado Pleno no Exterior
} 


\section{INTRODUÇÃO}

Parece notório que o movimento restaurativo ganhou espaço (social e jurídico) nos últimos anos, sendo amplificado em muitos países - a exemplo do impulsionamento dado pelo Poder Judiciário no Brasil, pautando a justiça restaurativa como um modelo factível de resolução de conflitos. A provocação desse ensaio destina-se a pautar a possibilidade de aplicação da justiça restaurativa - de seus valores, princípios e práticas - para conflitos de maior complexidade, cientes das limitações que o seu modelo interrelacional apresenta em situações nas quais os ofensores, as vítimas, as comunidades e os danos causados são de difícil (quiçá, de impossível) identificação. Nessa linha, o problema de partida detém-se na reflexão sobre a viabilidade de criação de uma justiça restaurativa socioambiental, aplicável para condutas ofensivas ao meio ambiente que, por sua vez, afetam a toda sociedade.

Entretanto, a novidade da justiça restaurativa e os desafios que a proposta encerra pressupõem, um passo antes, responder a questões elementares de sua aplicação na seara ambiental para refletirmos "se, como e em que medida a justiça restaurativa poderia oferecer uma abordagem mais inclusiva, abragente e efetiva" (Aertsen, 2018, p. 237, tradução nossa) ${ }^{1}$ na matéria?

Para assim proceder, o artigo delimita, no primeiro momento, o estado da arte do movimento restaurativo no Brasil, apresentando críticas relevantes para a sua compreensão situada no contexto nacional; na sequência, será destacada a necessidade de inovações teóricas que suportem novos modelos de administração do conflito penal no Sul periférico - uma vez que as (in)justiças sistêmicas socioambientais estão correlacionadas às populações vulneráveis, vítimas dos grandes conglomerados capitalistas que buscam a aquisição máxima de lucro através da exploração de recursos naturais. Posteriormente, apresentam-se as reflexões direcionadas ao desenvolvimento de uma nova gramática da justiça restaurativa, que (re)pensa as suas categorias analíticas a partir de uma maior interdisciplinariedade e criatividade necessárias à aplicação nesse emergente terreno que, numa perspectiva aprofundada, pode justificar uma nova ética ambiental fundada na participação social e na alteridade. Aqui, como citado por Braithwaite, pensamos como/se poderá ser possível "a mobilização do poder e da imaginação restaurativa pela humanidade a serviço da vida na terra" (2019, p. 9, tradução nossa $)^{2}$.

\section{JUSTIÇA RESTAURATIVA "À BRASILEIRA": OS PROCESSOS HEGEMÔNICOS DE IMPLEMENTAÇÃO DAS EXPERIÊNCIAS RESTAURATIVAS}

A justiça restaurativa no Brasil é fenômeno recente, ainda em constante desenvolvimento e transformação, justificando, portanto, necessárias reflexões nos seus âmbitos teóricos e práticos decorrentes das muitas incertezas que ainda circundam a matéria. Ressalta-se que foi a difusão de experiências sociais com características restaurativas - um movimento de base social (Aertsen, 2007: 96) - que incitou a atenção dos acadêmicos, razão pela qual se constituiu como "um conjunto de práticas em busca de teorias" (Sica, 2007: 10) que as enunciem.

No campo dogmático, a dificuldade de precisão na definição do conceito de justiça restaurativa suscita, por um lado, o problema da confusão dos seus significantes e propostas de fundo - ao mesmo tempo em que a sua fluidez e adaptação às necessidades econômicas, políticas e sociais dos contextos em que são inseridas viabilizam que estejam ajustadas aos díspares conflitos que

\footnotetext{
'Do original: "whether, how and to what extent restorative justice could offer a more inclusive, encompassing and effective approach?"

2Do original: "the mobilisation of the restorative power and the restorative imagination of humankind in service of life on earth". 
regulamentam ${ }^{3}$. Diante disso, defende-se que aspectos mínimos devem ser respeitados para delimitar e reconhecer uma prática como restaurativa (Oliveira, 2021): ela assim se classifica quando se destina à resolução de conflitos (penais) de forma diversificada daquela adotada pelo sistema penal tradicional, em virtude da alargada participação dos atores envolvidos no conflito (autor, vítima e comunidade) direcionadas à satisfação das suas específicas necessidades (reparação), efetivadas a partir de um processo dialogado e voluntário (Pelikan e Kremmel, 2017).

Sendo frequentemente associado às teorias abolicionistas, criminológicas críticas e vitimológicas, o modelo restaurativo de justiça não surgiu desvinculado das problemáticas afetas ao sistema criminal (Achutti, 2014), uma vez que, desde a década de setenta, as teorias supracitadas denunciavam que tal sistema se fundamenta e reproduz violências, encarcerando (em massa) populações que são vulneráveis e marginais ao capitalismo; por sua vez, a vitimologia destacou que a vítima é coisificada no curso do procedimento judicial e que, abandonada e sem voz, pouco participa e se satisfaz com os resultados advindos da sentença.

Assim, a justiça restaurativa se apresentaria como uma contraproposta à racionalidade punitivista que conduz o modelo dominante, na tentativa de implementar algo melhor do que o sistema penal. Justamente por isso, discussões sobre a reparação e a retribuição, sobre as finalidades da pena e as funções atribuídas à reparação ou, ainda, sobre a reincidência e a (re)estabilização do tecido social comunitário através de medidas desencarceradoras são constantemente travadas entre os entusiastas do novo modelo e os juristas mais conservadores. Isso porque, existe um espaço de intersecção entre o campo penal e o campo restaurativo que, por estarem em constante tensão (Oliveira, 2021), forjam iniciativas que tendem para a autonomia ou a completa subordinação das práticas restaurativas à racionalidade penal, a depender dos atores que conduzem o "locus" de inserção e determinam os conteúdos dessas novas ferramentas.

Como é notório em um país de dimensões continentais e de culturas plurais como o Brasil, não há que se falar em movimentos homogêneos e transversais de institucionalização das práticas restaurativas em desenvolvimento. Entretanto, é possível identificar uma relativa hegemonia de modelos e teorizações que reproduzem certas estruturas, conduzidas por semelhantes atores e que, tendencialmente, poderão ser colonizadas pelas lógicas do campo penal.

Partindo-se dessa premissa, e para fins especificamente metodológicos, pode-se afirmar que o desenvolvimento da justiça restaurativa no país ocorre em "dois tempos contínuos" (Andrade, 2018: 113, grifo nosso): o primeiro foi caracterizado como o período da "implantação" de experiências-piloto financiadas em parceria com o Ministério da Justiça, o Poder Judiciário e o Programa das Nações Unidas para o Desenvolvimento - PNUD, durante os anos de 2005 a 2010, como resultado do Projeto BRA/05/009 - Promovendo Práticas Restaurativas no Sistema de Justiça Brasileiro. Nessa fase, três projetos foram implementados e gerenciados por magistrados estaduais: a ação nominada "Justiça e Educação: uma parceria para a cidadania", foi desenvolvida na Vara da Infância e da Juventude de São Caetano do Sul, São Paulo; por sua vez, no Distrito Federal, a ação foi alicerçada junto ao Juizado Especial Criminal do Núcleo Bandeirantes; por fim, alocado na $3^{\text {a }}$ Vara da Infância e da Juventude de

\footnotetext{
${ }^{3}$ Não se ignora a existência de documentos internacionais que se destinam a conceituar ou, ao menos, indicar elementos de referência para a concepção do que a justiça restaurativa pode (ou não) ser. Nesse sentido, cfr. a "Recommendation CM/ $\operatorname{Rec}(2018) 8$ concerning restorative justice in criminal matters" de 3/10/2018, adotada pelo Comitê de Ministros do Conselho da Europa (https://search.coe.int/cm/Pages/result_details.aspx?Objectld=09000016808e35f3) ou, ainda, os "Principles on the use of restorative justice programs in criminal matters in 2002" da ONU que foi atualizado em 2020 (para a segunda edição, conferir: https://www.unodc.org/documents/justice-and-prison-reform/20-01146_Handbook_on_Restorative_Justice_Programmes. pdf? fbclid=IWAR3XCWwiLHIO_AHCj72il fltKH6d5VrzlwZbeuCsWSbELnw2FNivWS4Mgp0).
} 
Porto Alegre, Rio Grande do Sul, implementou-se o projeto "Justiça para o Século 21", voltado para os casos envolvendo jovens infratores (Andrade, 2018).

Se, no primeiro momento citado, coube ao Poder Executivo impulsionar a justiça restaurativa no país, a segunda fase (de 2010 em diante), que é demarcada pela "institucionalização-expansão" das práticas (Andrade, 2018:113, grifo nosso), dá-se sob o protagonismo do Poder Judiciário, que incentiva (e define como meta) a implementação de novas experiências nas varas e tribunais ao redor do país. Ademais, frente à inércia do Poder Legislativo, esse mesmo ativismo da magistratura estadual junto ao Conselho Nacional de Justiça (CNJ) culminou na edição de resoluções que servem de referência para novos programas experimentais - aqui, cita-se a normativa CNJ 125/2010 e a CNJ 225/2016, esta última tida como uma das mais importantes balizadoras da matéria.

Em apertada síntese, verifica-se no movimento nacional a atuação de específicos magistrados responsáveis pela implementação dos projetos, gestão das atividades, viabilização de ações destinadas à capacitação e adesão de voluntários para a consolidação das práticas. Há, então, uma concentração de funções nesses atores: os mesmos profissionais que sentenciam os casos nas suas jurisdições criminais são, muitas vezes, aqueles que também os selecionam, enviam para os projetos em experimentação e, ao final, homologam os seus resultados (Oliveira, 2021). Consequentemente, pode-se vislumbrar uma total inserção das experiências no âmbito do sistema penal, pouco anunciando o potencial de ruptura ou de transformação frente à sua lógica dominante.

A essa categoria de atores que protagonizam os cenários de implementação da justiça restaurativa, acrescentam-se também a hegemonia de práticas e de teorias que sustentam as suas narrativas (Oliveira, 2021). Apesar da pluralidade de instrumentos que consagram os valores e processos restaurativos, os modelos circulares adotados pelos magistrados - os peacemaking circles (círculos de construção de paz) (Pranis, 2010) - têm sido reiteradamente utilizados para os mais vastos tipos de criminalidade e de perfis de sujeitos envolvidos nos conflitos. Tais metodologias de aplicação se sustentam em teorias estrangeiras - especialmente derivadas de países de língua anglófona, desenvolvidas por atores como Howard Zehr, Kay Pranis, Marshal Rosenberg, dentre outros - que por vezes destoam das origens e dos contextos socioculturais para as quais foram pensadas.

Em outras palavras, refletir sobre os caminhos de uma brasilidade restaurativa demanda de seus intervenientes o ato de pensar uma relação dialógica, de intercâmbio (tradução) e complementação entre saberes (Santos, Araújo e Baumgarten, 2016: 17), que se opõe a uma singela subordinação, da importação do conhecimento desde uma perspectiva hierárquica, reducionista e universal, impositiva do que a justiça restaurativa deve ser, sem acentuar as diferenças existentes entre estados centrais e periféricos. Restando ausente a tradução crítica destas perspectivas às necessidades dos contextos latinos em que são implementadas, seus resultados podem, quando/se avaliados, produzirem respostas indiferentes (porque não estruturais) às necessidades das vítimas, das comunidades e dos ofensores que partilham da experiência danosa.

Nos terrenos em que as propostas restaurativas são adotadas verifica-se a urgência na mobilização de conhecimentos plurais destinados à produção de métodos e indicadores de avaliação, aptos a regulamentação de "boas práticas" cientificamente evidenciadas a partir das necessidades das problemáticas nacionais, sob pena de que continuem a reproduzir discursos e racionalidades penais, difundidas por classes privilegiadas de atores que não discutem questões estruturais (dos conflitos e dos contextos) para as quais podem ser aplicadas. 
Aqui, a ausência de tradição empírica na matéria faz com que persigamos, como meta, a produção de um conhecimento restaurativo alicerçado em experiências e observações que serão adequados para compreendermos, efetivamente, quais danos as pessoas querem que sejam reparados e de qual justiça se fala no caso concreto.

\section{PROSPECTOS PARA A CONSTRUÇÃO DE UMA "SOUTHERN GREEN CRIMINOLOGY AND VICTIMOLOGY"4 (SUSTENTÁVEL POR PRÁTICAS RESTAURATIVAS)}

Se as críticas exaustivas às seletividades que estruturam o sistema de justiça penal suscitou a construção de modelos que lhe pudessem ser alternativos - tal qual, aqui, a justiça restaurativa segue-se o mesmo pressuposto para refletirmos sobre a necessidade de novas teorias e tecnologias destinadas à proteção do meio ambiente e a atuação sustentável ${ }^{5}$ do mercado. Para tanto, queremos aqui afastar os imperialismos criminológicos (Agozino, 2003) para repensar o fenômeno desde os nossos quintais.

Nessa linha, emprestamos as críticas das "Criminologias do Sul" (Carrington, Hogg e Sozzo, 2016) que denunciam como certas epistemologias forjaram um modelo universal de compreensão dos processos de criminalização de condutas e de sujeitos, desconsiderando a tradição histórica de cada espaço social. Por aproximação às necessidades de (re)pensar a partir de uma realidade marginal, faz-se urgente a produção de um conhecimento (plural) que suporte "inovações teóricas" que desafiem as delimitações de conceitos e métodos ditados pelas experiências do Norte, ao passo em que também faça as devidas correções e avanços empíricos, "descolonizando" e "democratizando" as suas ferramentas (Carrington, Hogg e Sozzo, 2016: 15) ${ }^{6}$.

Se, nos anos noventa, o surgimento da Criminologia Verde (Lynch, 1990), resultou da necessidade de "estudar as transgressões cometidas contra ecossistemas, pelos seres humanos e não-humanos em interação entre si e com o ambiente que os rodeia" (Rodríguez Goyes, 2019: 3, tradução livre $)^{7}$, também transferimos o argumento da produção de "epistemologias do sul" (Santos, 2014) para a construção de uma Criminologia Verde do Sul (Southern Green Criminology) (Rodríguez Goyes ${ }^{8}$, 2019) que possa auxiliar a compreensão do atual contexto de violações sistemáticas ao ambiente e construir estratégias de resistência nos países periféricos.

Enquanto país marginal (do Sul Global) que aloca em suas dimensões os maiores patrimônios ambientais, sabe-se que o Brasil tem ocupado as manchetes nacionais e internacionais ${ }^{9}$ pela inércia frente à devastação da Amazônia e do Pantanal, do genocídio indígena (agravado com a sua contaminação pelo Covid-19), pelos danos causados aos ecossistemas marinhos em virtude dos reiterados

\footnotetext{
${ }^{4}$ Criminologia e Vitimologias Verdes do Sul Global

${ }^{5}$ Sobre medidas de sustentabilidade ambiental para o novo milênio, cfr. a Agenda 2030 da ONU - disponível em: http://www. agenda2030.org.br/sobre/

${ }^{6}$ A criminologia do Sul descrita por Carrington, Hogg e Sozzo (2016: 15) "[...] is a theoretical project. It seeks to encourage and support theoretical innovation and not just the application of theory imported from the global North. Lastly southern criminology is a democratizing epistemology that challenges the power imbalances which have privileged knowledges produced in the metropolitan centers of the global North. Its purpose is not to dismiss the conceptual and empirical advances that social science has produced over the last century but to correct biases by decolonizing and democratizing the toolbox of available criminological concepts, theories and methods".

${ }^{7}$ Do original: "to study transgressions committed against ecosystems, human beings and nonhuman beings in the interactions between humans and their natural surroundings"

${ }^{8}$ Ironias à parte, a proposta de uma criminologia ambiental do Sul tem sido desenvolvida por Goyes, investigador que apesar de ter origens latinas, fez o seu percurso acadêmico na Universidade de Oslo - Norvega.

${ }^{9}$ Como exemplo, conferir https://www.theguardian.com/world/2021/jan/23/jair-bolsonaro-could-face-charges-in-the-hagueover-amazon-rainforest
} 
derramamentos de petróleo e seus derivados, pelo colapso de barragens gerenciadas por empresas mineradoras, tal qual ocorrido em Minas Gerais, nas cidades de Mariana (2015) e Brumadinho (2019). Em outras palavras, pode-se afirmar que os modelos de proteção ou de gestão de crises/tragédias se existentes, são visivelmente ineficientes - inclusive, no âmbito jurídico, frente a demora da responsabilização judicial das pessoas (físicas e jurídicas) envolvidas nestes casos.

Não sem razão, Saad-Diniz e Gianecchini (2021) diagnosticaram a crescente "regressão regulatória" dos marcos de tutela ambiental ${ }^{10}$, ou seja, o tendente retrocesso das (poucas) conquistas normativas protetivas da natureza que existiam no ordenamento jurídico, reflexo direto do déficit democrático atualmente instaurado no Brasil. Significa dizer, ainda citando Saad-Diniz (2020: 2), que “(...) não há no horizonte políticas regulatórias ou mesmo iniciativas corporativas minimamente convincentes e com algum impacto na redução da devastação ambiental”.

Nesse cenário, importa produzir modelos de resistência no âmbito da resolução de conflitos para serem contrapostos ao projeto condutor do cenário brasileiro, que repaginando formas de controle (pós)coloniais e opressoras, coloca o meio ambiente (e, consequentemente, os sujeitos vulneráveis que nele habitam) em direta dependência e subordinação aos interesses dos grandes conglomerados corporativos, controladores do capital. Se, no âmbito governamental, o calculado desinteresse na busca por uma justiça ambiental parece ser a opção politicamente instaurada, deve-se pensar, entre os demais atores desse campo, como tornar as corporações ambientalmente sustentáveis e, se assim o forem, quais as melhores práticas - para além daquelas legalmente definidas - serão aptas a efetivar as responsabilidades (penal e social?) delas exigíveis.

No mesmo sentido, para pensarmos em ferramentas que promovam a reparação tanto do dano ambiental como dos efeitos que as ações causaram às comunidades de sujeitos vulneráveis, faz-se também uso da interdisciplinaridade entre a justiça restaurativa e a vitimologia, que não deixa de correlacionar os comportamentos ofensivos à natureza com a sua população socialmente marginalizada, selecionada em função da classe, raça, etnias, gênero e dependências socioeconômicas herdadas de processos complexos de colonização, cujo passado histórico insistimos em reproduzir.

Mais do que isso, renova-se a possibilidade de desenvolvimento de uma perspectiva vitimológica que não se afasta da ecojustice, ou seja, que se direcione, de forma criativa, também a pensar numa perspectiva ecocêntrica, no valor ético tributável à natureza e de como esta tem sido vitimizada. Não sem razão, Braithwaite aponta que a justiça restaurativa socioambiental carrega consigo a possibilidade de renovação das relações entre sujeito e ambiente - reparando os danos causados pelo Antropoceno, era na qual instrumentalizamos os recursos naturais sob a narrativa do desenvolvimentismo e do progresso - para, além disso, propor que esses modelos promovam "a cura dos ecossistemas terrestres e das relações humanas com a natureza e com o outro" (2019: 9, tradução nossa) ${ }^{11}$.

\footnotetext{
${ }_{10}$ Para além do desmonte do IBAMA, recentemente a Resolução 500/2020 do Conselho Nacional do Meio Ambiente (Conama), revogou as Resoluções 284, 302 e 303 que regulamentavam o licenciamento ambiental de atividades de irrigação e traziam definições e especificações protetivas relativas às áreas de preservação permanente (APPs), como restingas e manguezais. Tramitam no Supremo Tribunal Federal duas Arguições de Descumprimento de Preceito Fundamental (748 e 749 ) contra a aludida norma. Informações em: http://portal.stf.jus.br/noticias/verNoticiaDetalhe.asp? idConteudo=452777\&ori=1. Acesso em 04/10/2020.

11 "healing earth systems and healing the relationship of humans with nature and with each other"
} 


\section{EXPLORANDO AS POTENCIALIDADES DE UMA "JUSTIÇA RESTAURATIVA CORPORATIVA E SUSTENTÁVEL"}

A partir da análise dos terrenos em que a justiça restaurativa se desenvolve, percebe-se, diante das hegemonias citadas, a sua tendente colonização pelo sistema penal - com as vantagens e desevantagens que disso decorra (Oliveira, 2021). Os modelos nacionais são, em regra, direcionados ao tratamento de conflitos de menor potencial ofensivo - que, em muitos casos, poderiam ser resolvidos fora do âmbito jurisdicional. Nesse sentido, delineou-se uma perspectiva que denominamos "clássica" ou "de baixa complexidade" no uso dessas experiências e que, no intuito de explorar os seus limites e as suas potencialidades, precisaremos ultrapassar.

Para tanto, faz-se mister o afastamento das características que conformam uma epistemologia da justiça restaurativa numa perspectiva mais "conservadora", por serem aplicadas a crimes de diminuta potencialidade lesiva, em que estão devidamente individualizados os atores envolvidos na ação e cujos danos podem ser mensuráveis e identificados para serem satisfeitos, para questionarmos como poderiam as suas práticas serem aplicadas em casos ambientais.

Se a novidade da matéria, por si só, encerra muitos desafios, situar a justiça restaurativa em cenários nos quais decorrem conflitos de alta complexidade demanda o desenvolvimento de novos marcos regulatórios e cooperativos num tripé (ideal) entre particulares, Estado e empresas, sustentados em formas mais sofisticadas (Saad-Diniz, 2020)12 e participadas de controle social. Em outras palavras, importa refletir como/se é possível desenvolver teorias e práticas que conjuguem formas diversificadas de controle social (formal e informal), nos quais participam diversos atores envolvidos nos conflitos ambientais - em especial, aquelas comunidades tradicionais que diretamente se relacionam com a natureza - ou que são interessadas na sua proteção - tais como organizações do terceiro setor, advocacy, etc.

Nesse locus, repensar (de forma interdisciplinar) as categorias ou os elementos fundantes da justiça restaurativa que a conduzem a uma outra gramática (frise-se, que não defendemos que seja melhor ou pior do que as epistemologias já delineadas) deve tornar-se o exercício primeiro dos seus entusiastas, cientes de que a sua construção não pode estar apartada de estudos empíricos resultantes de um permanente diálogo entre teoria e prática. Seria então viável alocar a justiça restaurativa em espaços de maior complexidade (aqui, o espaço corporativo e de direta correlação com conflitos que afetam o ambiente) do que àqueles em que têm sido inseridos no Brasil, construindo uma epistemologia que atenda às suas demandas teórico-práticas e metodologias de avaliação e monitoramento desses resultados? São perspectivas a seguir refletidas.

\section{OS PROTAGONISTAS DO PROCESSO RESTAURATIVO: OFENSOR, VÍTIMA E COMUNIDADE}

Nils Christie (1986) já destacava que o modelo de construção de vítimas ideais - sustentando num perfil estereotipado sobre as pessoas que são alvos dos crimes tradicionais - destoa em muito da realidade social e complexa em que atuamos e precisa ser ultrapassado, uma vez que essa rotulação "depende de processos sociais de identificação e definição, não raramente determinados por interesses culturais, políticos ou econômicos adquiridos" (Aertsen, 2018: 237, tradução nossa) ${ }^{13}$. Nesse passo, identificar quais/quem são as vítimas concretas envolvidas nessas ações complexas e

\footnotetext{
12 SAAD-DINIZ, Eduardo. Justiça Restaurativa Empresarial: problemas e desafios. Evento on line. IBDPE, 1 de outubro de 2020. Disponível em: https://www.youtube.com/watch? v=u19kzWk3Z0c\&t=10503s. Acesso em 4/10/2020

13 "depends on social processes of identification and definition, not seldom determined by vested cultural, political or economic interests"
} 
entender quais são as necessidades decorrentes do impacto causado pela ação, para identificar o que pretendem e quais respostas podem obter ao aceder a programas de características restaurativas, parece traduzir um desafio inicial.

Ainda numa perspectiva ecocêntrica de construção da justiça, White (2018: 241) aponta que, em matéria ambiental, podemos classificar as vítimas em humanas e não-humanas: falamos de uma "justiça ambiental" (environmental justice), no primeiro caso; e em justiça ecológica (ecological justice) (quando as vítimas são ecossistemas específicos) e justiça das espécies (species justice) (quando as vítimas são animais ou plantas) ao retratarmos os modos de afetação da natureza ${ }^{14}$. Aqui, abre-se também o espaço para problematizarmos as relações de colonialidade que historicamente sustentam os modos de exploração dos recursos ambientais, colocando, obviamente, o ecossistema como vítimas diretas dessas formas de agir.

Ao pensarmos no comportamento corporativo socialmente relevante (e, danoso), dentro desses processos de vitimização, como citado por Nieto Martín (2018: 31) e Varona (2020: 667), as vítimas podem ser absolutamente invisíveis, seja em decorrer do desequilíbrio de poder que sustenta a relação entre a vítima e o ofensor, seja porque, como relatado também por Aertsen (2018: 237), a coletivida$\mathrm{de}^{15}$ não se sente diretamente afetada pelo problema ambiental face à invisibilidade do dano, não se percebendo vítimas dos comportamentos.

Da ação socialmente danosa praticada por empresas contra o ambiente, podem resultar vítimas internas ou externas às corporações (trabalhadores da instituição, fornecedores, ou, no segundo caso, podem congregar os lesados que com ela possuam alguma relação de proximidade familiar ou comunitária) (Aertsen, 2018: 247). Ainda, essas vítimas podem ser economicamente dependentes dos seus ofensores (Saad-Diniz, 2020: 3), razão pela qual os limites da aceitação voluntária da qual decorre a participação dos protagonistas e a horizontalidade que conduz a prática restaurativa poderiam também ser questionados.

Como, então, inserir essas vítimas difusas (humanas e não-humanas), de difícil identificação, ativamente participando nos modelos de justiça restaurativa?

Em âmbito mais abrangente, ao pensar na comunidade como vítima (já agora, não aquela de proximidade citada por McCold (1996) e que balizam a participação de seus representantes nos círculos restaurativos) para serem nela incluídos os sujeitos invisíveis e as futuras gerações, como participariam e teriam legitimidade para dialogarem no âmbito das experiências restaurativas? No mesmo sentido, como identificar os atores que representam as futuras gerações, para serem inseridos nas práticas restaurativas ${ }^{16}$ Como definir a legitimidade dessa participação por sub-rogação? Faz sentido que tais vítimas se encontrem para a construção de narrativas futuras, voltadas à manutenção de "memórias" dos traumas e das tragédias que são constitutivas das histórias daqueles espaços e identidades?

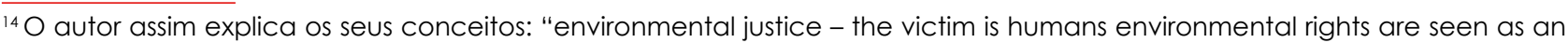
extension of human or social rights so as to enhance the quality of human life, now and into the future; "ecological justice - the victim is specific environments human beings are merely one component of complex ecosystems that should be preserved for their own sake; Species justice - the victim is animals, and plants animals have an intrinsic right not to suffer abuse, and plants not to suffer the degradation of habitat to the extent that threatens biodiversity loss." (White, 2018: 241)

${ }^{15}$ Aertsen (2018) especifica que podemos falar de vítimas primárias (aquelas diretamente afetadas pela ação), secundárias (seus familiares e demais comunidades de próximos) e vítimas terciárias, que, sendo aleatórias, representam toda a sociedade (presente e futura) que suportará os efeitos do dano causado ao ambiente.

${ }^{16}$ Sobre o problema, White ao ser entrevistado por Dzur (2021) também se manifesta: "The way I approach it is to initially describe those who speak for nature as advocates and those who speak about nature as experts". It is really about dialogue and making sure we listen to the variety of voices when we talk about speaking for nature".
} 
Sendo a corporação identificada como ofensora, como inseri-la no modelo restaurativo, ou seja, como fazer com que assumam responsabilidades para além daquelas restritamente previstas em lei? Não sem razão, Braithwaite (2019: 10) alerta para a criação de estratégias que viabilizem a inserção da empresa em práticas restaurativas: pode tal adesão ser atrativa à sua reputação e imagem pública, especialmente frente a política adotada junto a seus consumidores; esse efeito proativo de responsabilidade social poderia resultar em melhor relacionamento com o governo, especialmente diante de processos de licitação ou de autorização para a aquisição de licenças de atuação em específicos setores.

Assim, seria viável uma construção teórica e cuja incidência de práticas restaurativas estivesse situada no ambiente corporativo - de modo pré-conflitual, a partir do estabelecimento de uma cultura organizacional eticamente sustentada, cuja resolução de situações problemáticas por vias restaurativas passe a ser pautada nos programas de conformidade construídos pelas empresas - ou, ainda, numa fase pós-conflitual, em que a restauração dos danos decorrentes da infração (aqui, para o nosso interesse, na seara ambiental) podem dar pistas acerca dos efeitos de transformação social e de empoderamento que esses modelos podem (porventura) suscitar?

Nessa pauta, faz sentido falar de aplicação de justiça restaurativa pelas empresas que devem ser socialmente responsáveis por danos na seara ambiental? Sua aplicação prévia ao conflito, a partir de programas de conformidade, pode incutir na empresa o dever de diálogo e de recuperação dos danos causados, viabilizando, mais facilmente, políticas públicas e sociais de reestruturação dos espaços comunitários atingidos, de forma mais democrática? A utilização de mecanismos restaurativos para lidar com os danos trazem resultados mais positivos aos envolvidos?

Não sem razão, pensa-se na possibilidade de uma convergência de modelos diferenciados de controle social, que dispõem de seus aparelhos formais (aqui, associados às dinâmicas judiciais) e informais (centrando-se na participação da comunidade e nas instituições públicas e privadas a partir de estratégias restaurativas) e que se direcionam a produção de novas culturas corporativas diretamente correlacionadas com os problemas sociais e ambientais nacionais, comprometidas com a reparação dos danos causados. Quais transformações sociais poderiam decorrer da utilização desses modelos híbridos? Poderiam as empresas adotar medidas de conformidade mais satisfatórias a partir das aprendizagens do caso que seriam difíceis de advirem apenas com a prolação da sentença, finalmente firmando uma cultura organizacional pautada na ética ambiental? Como poderiam atuam em conjunto para evitar/gerenciar crises ambientais, de forma mais plural e democrática?

Em síntese, aludindo aos ensinamentos críticos da justiça restaurativa, da criminologia e vitimologia, faz-se essencial identificar que os processos de vitimização podem resultar de um agir/não agir feito "pela empresa, contra a empresa ou dentro da empresa" (Saad-Diniz 2019: 152). Obviamente, as formas de atuação no âmbito restaurativo não podem deixar de considerar, no caso concreto, quais são os atores envolvidos na ação - afastando-se, de imediato, a lógica do one fits all para os modelos de solução de todos esses casos complexos.

Todas essas questões surgem como pautas a serem refletidas e aprofundadas nesse novo momento de compreensão das potencialidades e dos alcances da justiça restaurativa - obviamente, para assim proceder de forma científica, importa coletar e analisar dados empíricos representativos dos problemas anunciados. 


\section{A DIMENSÃO DO DANO E AS REPARAÇÕES (POSSÍVEIS?)}

De acordo com Bolívar (2019: 3), existem imprecisões quanto ao conceito e ao que se pode alcançar, no âmbito da justiça restaurativa, com a restauração ou a reparação $0^{17}$ dos danos (e, obviamente, sobre quais danos seriam estes e o que significaria a sua restauração para diferentes protagonistas - vítima, ofensor e comunidade). Nessa linha, interessante é a posição de Pemberton (2019: 15, tradução nossa) ao criticar que o elemento-chave do campo seja a "restauração", uma vez que defende a impossibilidade de que os sujeitos retomem o seu modo-de-ser no mundo tal como antes da ofensa suportada. Propõe que mais vale a opção por uma "re-storing" 18 (Pemberton, 2009: 15) - em que se prima pela construção de narrativas nas quais as consequências dos danos ficam integradas à história pessoal (não sendo dela apagada), transformando-as em experiências positivas que reinventam os sujeitos a partir das aprendizagens derivadas da ação lesiva.

Obviamente, sendo esta dificuldade sentida no modelo tradicional de aplicação da justiça restaurativa - onde mais facilmente os prejuízos são identificávies - ainda mais complexa se torna a definição de quais são as dimensões do dano causado à natureza e quais são as possíveis formas de restauração. Aqui, categorizar os vários tipos de danos, suas intensidades e os modos como atingem as pessoas e a natureza, exige um exercício criativo e inovador de atribuição de responsabilidades (Saad-Diniz, 2019: 15): as lesões podem ser de difícil mensuração imediata (pelo seu nível de complexidade), podem ser postergadas no tempo de forma ilimitada (Aertsen 2020), podem ter um conteúdo não mensurável (pense, por exemplo, no dano à memória e à tradição histórica dos povos originários), além de atingir diferentes comunidades em espaços sociais distintos entre si; podem exigir a construção de políticas de prevenção nas quais restam ausentes recursos públicos para tanto, dentre outros.

Obviamente, é preciso identificar o quê é passível de recomposição e como dever ser feita a reparação para que os seus protagonistas restem satisfeitos (e, em outras palavras, não se sintam novamente injustiçados e desempoderados). Aqui, a alocação de recursos financeiros para a reconstrução das comunidades afetadas, nas quais participam, democraticamente, de modelos de gestão e governança que ajudem a reconstruir a vida dos prejudicados, parecem efetivar um maior compromisso ético e social de atuar de acordo com uma cultura de legalidade e em respeito aos ditames democráticos.

Entretanto, não raro, pode-se estar diante de reparações pouco prováveis de serem conseguidas - pensemos numa espécie dizimada, ou quando se inviabiliza o correr natural de um rio, dentre outros - dificultanto a restauração do ambiente e do modo de vida dos atores sociais.

Em sociedades pós-modernas e marcadas pela inexistência de fronteiras, os conflitos podem também serem alargados no espaço e serem praticados em um estado-nação, atingindo, de forma transnacional, contextos que ultrapassam as fronteiras do país. Nestes casos, como descrito por Varona (2020: 668), faz-se necessária a incidência de normativas de diferentes ordenamentos jurídicos, sendo, portanto, mais difícil a responsabilização. Como identificar a extensão do dano e, mais, dialogar com todos os sujeitos prejudicados? Ao noticiarmos, diariamente, o desmatamento das

\footnotetext{
${ }_{17}$ A "restauração" (restoration) tem sido mais associada ao seu componente simbólico e emocional do conflito, ao passo que a reparação (reparation) atrela-se a danos que podem ser mensuráveis materialmente (Bolívar, 2010: 239) ou que podem ser remediados com a entrega de bens ou prestação de serviços (2007). Não obstante a diferença conceitual, os termos serão usados de forma indistinta por muitos entusiastas da matéria, tomado, de forma geral, a restauração como elemento de composição de danos (de quaisquer tipos) que sustenta o campo restaurativo.

${ }^{18} \mathrm{O}$ autor faz a crítica da palavra e expressão "restoring" (como uma volta ao "status quo") para adequá-la a um "re-storing", ou seja, para que o sujeito transforme a sua experiência traumática e redesigne o seu modo de ser no mundo - o que mais se aproximaria dos valores e ideais da justiça restaurativa.
} 
florestas tropicais, não restariam atores da comunidade internacional também prejudicados? Como recuperar o dano que atinge diferentes populações e países através da métrica da justiça restaurativa?

\section{CONCLUSÃO}

Em recente entrevista, Rob White (2021) questionou qual é a proposta que se pretende construir e o que queremos alcançar quando pensamos em unir a justiça restaurativa e a justiça ambiental. Ao pensar nesta pauta - ou, de no primeiro momento, problematizar sobre ela - colocamos nesse texto algumas dificuldades e desafios que deverão ser enfrentados diante da reunião de duas epistemologias que giram e unem esforços em torno de um mesmo tema: a proteção do ambiente e dos sujeitos socias.

Faz-se importante uma ressalva: compreender o atual estado de degradação ambiental suscita perceber diagnósticos plurais e por vezes interligados a situações características da sociedade de risco e, portanto, conectadas à atuação empresarial. O êxito da modernidade tecnológico-científica revelou, como contraponto, o esvaziamento da consciência ecológica e político-social do sujeito. A necessidade de retomada da relação de cuidado com a natureza - que poderia ocorrer por intermédio da afirmação de uma ética do cuidado viabilizada pelos modelos de justiça restaurativa - resulta do esgotamento dos recursos essenciais à constituição da subjetividade, não apenas relacionadas com o momento presente, mas ampliadas às futuras gerações.

Demonstrou-se que diante da existência da necessidade de reparação de danos complexos e temporalmente indefinidos; de vítimas e ofensores coletivos ou institucionais e de comunidades que muitas vezes não são identificáveis; de comportamentos que atentam, de forma grave, à bens jurídicos coletivos, faz pouco sentido a aplicação da justiça restaurativa "clássica" como tem sido implementada no Brasil. Propõe-se, então, uma necessária reflexão acerca dos seus elementos fundantes, categorias de práticas e formas de aplicação, que dialoguem com as inovadoras problemáticas que foram aqui mencionadas.

Se afastamos abstrações e universalismos teóricos, para utilizarmos de propostas teóricas e práticas que olhem para os contextos nacionais, para as suas demandas e carências - especialmente frente ao esgotamento dos recursos naturais que se tem verificado - a escolha de específicos contextos, que foram severamente afetados por desastres ambientais, poderá dar amostras das possibilidades (ou não) de intervenções restaurativas.

Entretanto, ainda estamos distantes de construir indicadores que sejam aptos a sustentar metodologias de avaliação e monitoramento de práticas restaurativas nacionais (sejam em contextos complexos ou não), para conhecer os seus potenciais, sua efetividade, seus resultados e corrigir os seus desvios. Ao que parece, precisamos, então, pautar o tema, discuti-lo nos espaços acadêmicos e institucionais, no intuito de compreender a eficácia (ou não) do modelo aplicado na seara ambiental.

\section{REFERÊNCIAS}

AERTSEN, IVo. Restorative Justice for victims of corporate violence. In MAZZUCATO, Cláudia (et al) (org). Victims and corporations: legal challenges and empirical findings. Milano: Wolters Kluwer, 2018, p. 235-358

AERTSEN, IVo. Restorative justice through networking: a report from Europe. In: E. Van Der Spuy, PARMENTIER, Stefan e DISSEL, A. (Eds.). Restorative justice: politics, policies and prospects. Cape Town: Juta \& Co, 2007, p. 91-112 
AGOZINO, Biko. Counter-Colonial Criminology: A Critique of Imperialist Reason. Pruto Press: London, 2003

ANDRADE, Vera Regina Pereira de (Coord.). Relatório analítico propositivo "Justiça Pesquisa": direitos e garantias fundamentais - pilotando a justiça restaurativa: o papel do Poder Judiciário. Conselho Nacional de Justiça, 2018. Disponível em https://www.cnj.jus.br/wp-content/ uploads/2011/02/722e01 ef1ce422f00e726fbbee709398.pdf.

BOLÍVAR, Daniela. Restoring Harm. A Psychosocial approach to victims and Restorative justice. London: Routledge, 2019.

BRAITHWAITE, John; FORSYTH, Miranda e CLELAND, Deborah. Restorative environmental justice: An introduction. In PALI, Brunilda e BIFFI, Emanuelle (eds.). Environmental Justice Restoring the Future. Towards a restorative environmental justice praxis. Leuven: European Forum for Restorative Justice, 2019, p. 8-12.

CARRINGTON, Kerry; HOGG, Russel e SOZZO, Máximo. Southern Criminology. The British Journal of Criminology, 2016, 56 (1), 1-20. https://doi.org/10.1093/bjc/azv083.

CHRISTIE, Nils. Christie. The Ideal Victim. In: FATTAH, Ezzah (eds). From Crime Policy to Victim Policy. Basingstoke: Macmillan, 1986, p. 17-30.

DZUR, Albert. A talk with Rob White. The International Journal of Restorative Justice, 1, 2021.

LYNCH, Michael. The Greening of Criminology: A Perspective on the 1990s'. Critical Criminologist, $v$. 2, n. 3, p.3-12, 1990.

MCCOLD, Paul. Restorative justice and the role of the community. In: GALAWAY, Burt; HUDSON, John. Restorative Justice: International Perspectives. Monsey, New York: Criminal Justice Press, 1996, p. 85-101.

NIETO MARTíN, Adán. Empresas, víctimas y sanciones restaurativas: cómo configurar un sistema de sanciones para personas jurídicas pensando en sus víctimas? In: SAAD-DINIZ, Eduardo; LAURENTIZ, Victoria Vitti de (org). Corrupção, direitos humanos e empresa. Belo Horizonte: D'Plácido, 2018, p. 31-46.

OLIVEIRA, Cristina Rego de. Justiça Restaurativa Aplicada. Estudo de Caso das Experiências do Brasil e de Portugal. São Paulo: Blimunda, 2021 (no prelo)

PELIKAN, Christa; KREMMEL, Katrien. Lifeworld, Law and Justice. In: AERTSEN, IVo; PALI, Brunilda. Critical Restorative Justice. Oxford: Hart Publishing, 2017, p. 159-174

PEMBERTON, Antony. Time for a rethink: victims and restorative justice. The International Journal of Restorative Justice, 2(1), 13-33, 2019.

PRANIS, Kay. Processos circulares. (T. Van Acker, Trad.). São Paulo: Palas Athena. (Série Da Reflexão à Ação), 2010.

RODRÍGUEZ GOYES, David. A southern green criminology: Science against ecological discrimination. Bingley: Emerald, 2019

SAAD-DINIZ, Eduardo. Vitimização corporativa e dependência comunitária na criminologia ambiental: 0 acerto de contas com os desastres ambientais. Boletim do IBCCRIM, 27, n. ${ }^{\circ} 327$, fev., 2020, p. $2-5$.

SAAD-DINIZ, Eduardo. Vitimologia Corporativa. São Paulo: Tirant to Blanch, 2019. 
SAAD-DINIZ, Eduardo; GIANECCHINI, João Victor Palermo. The gears of environmental victimization. International Review of Penal Law, 2021 (forthcoming)

SANTOS, Boaventura de Sousa. O direito dos oprimidos. Sociologia Crítica do Direito 1. São Paulo: Cortez, 2014.

SANTOS, Boaventura de Sousa; ARAÚJO, Sara; BAUMGARTEN, Maíra. As epistemologias do Sul num mundo fora do mapa. Sociologias, 18, (43), 14-23, set-dez, 2016.

SICA, Leonardo. Justiça restaurativa e mediação penal: o novo modelo de justiça criminal e de gestão do crime. Rio de Janeiro: Lumen Juris, 2007

VARONA, Gema. Restorative pathways after mass environmental victimization: Walking in the landscapes of past ecocides. Oñati Socio-legal Series, 10 (3), 2020, p. 664-685. https://doi. org/10.35295/osls.iisl/0000-0000-0000-1044e

WHITE, Rob. Green victimology and non-human victims. International Review of Victimology 2018, Vol. 24(2), p. 239-255 